\title{
Aminergic Influences on Intravenous Cocaine Self-Administration by Rhesus Monkeys ${ }^{1}$
}

\author{
MARVIN C. WILSON ${ }^{2}$ AND CHARLES R. SCHUSTER ${ }^{3}$ \\ Department of Pharmacology, University of Michigan, Ann Arbor, Michigan
}

(Received 21 January 1974)

\begin{abstract}
WILSON, M. C. AND C. R. SCHUSTER. Aminergic influences on intravenous cocaine self-administration by rhesus monkeys. PHARMAC. BIOCHEM. BEHAV. 2(5) 563-571, 1974. - Earlier observations have demonstrated that when allowed limited daily access to cocaine, monkeys self-administer approximately the same amount of cocaine daily. Treatment with neuroleptic agents increases the frequency of this behavior which could be interpreted as resulting from an antagonism of the reinforcing actions of cocaine. The present paper demonstrates that agents known to alter central aminergic systems affect cocaine self-administration. Acute treatment with pargyline $(50$ and $100 \mathrm{mg} / \mathrm{kg})$ decreased the behavior; DL alpha-methylparatyrosine $(50 \mathrm{mg} / \mathrm{kg})$ increased the behavior. Treatment with the peripheral alpha adrenergic blocking agents phentolamine and phenoxybenzamine $(0.5-8.0 \mathrm{mg} / \mathrm{kg})$ did not significantly alter the behavior. Chronic treatment (5-10 days) with reserpine $(0.1-1.0 \mathrm{mg} / \mathrm{kg})$ produced an initial increase in selfadministration to which tolerance developed. Upon discontinuation of reserpine treatment, cocaine self-administration was decreased below baseline levels. Results tend to implicate either dopamine or norepinephrine as mediators of either cocaine-based reinforcement or of the other effects of cocaine which may regulate the frequency of its administration. Results were discussed in relation to those obtained from clinical studies in which drug effects on amphetamine-induced euphoria were ascertained.
\end{abstract}

Cocaine self-administration Psychomotor stimulant Pargyline Phentolamine Drugs as reinforcers Phenoxybenzamine Alpha methylparatyrosine Reserpine Denervation supersensitivity

THE intravenous self-administration of psychomotor stimulants by rhesus monkeys was originally demonstrated by Deneau et al. [3]. These investigators reported that the intravenous administration of cocaine and d-amphetamine initiated and maintained lever-pressing behavior. Several researchers $[4,9,10,12,15,17]$ have further demonstrated in both rats and rhesus monkeys that, when allowed daily limited access to the drug, the amount selfadministered per day was fairly constant within a subject. Total daily drug intake did not appreciably vary even though the dosage per injection or the size of a fixed ratio schedule of reinforcement were altered over a wide range of values. The mechanisms underlying this behavioral stability have not been ascertained but it has been hypothesized that in addition to the positive reinforcing actions, that aversive or behavioral disrupting effects of these compounds limit or regulate the frequency of the behavior.

Since animal self-administration experimentation is viewed by some as a model with which to study factors related to clinical drug abuse, it seemed reasonable to conduct studies to determine whether the reinforcing actions of psychomotor stimulants could be altered by treatment with other drugs. This method of experimentation could be utilized to determine if specific agents could antagonize the reinforcing efficacy of these compounds. Such agents might have clinical usefulness in the treatment of stimulant drug dependence.

Attempts to alter the stability of intravenous psychomotor stimulant self-administration by the administration of other drugs as pretreatment medication prior to initiating a drug access period, have met with some success. Acute pretreatment with $\alpha$-methylparatyrosine (AMPT) has been demonstrated to increase intravenous methamphetamine self-administration in rats [11] while intraperitoneal methamphetamine pretreatment decreased the frequency of this behavior and pretreatment with 1-dopa had no significant effect. Data demonstrating the ability of AMPT to antagonize both the primary and secondary reinforcement associated with intravenous d-amphetamine self-administration in rats have also been obtained [1,2].

Since many of the behavioral and physiological actions of the psychomotor stimulants have been attributed to

\footnotetext{
${ }^{1}$ This research was supported by NIMH grant numbers 12094 and 18245 .

${ }^{2}$ Presently located in the Department of Pharmacology, School of Pharmacy, University of Mississippi, University, Miss. 38677 (Send Reprint Requests).

${ }^{3}$ Presently located in the Departments of Psychiatry and Pharmacology, University of Chicago, Chicago, Illinois 60637.
} 
either an increase in adrenergic or dopaminergic activity, the following study was conducted in an attempt to provide additional data regarding the neurochemical basis of the reinforcement mechanisms associated with psychomotor stimulant self-administration. Furthermore, since previous data obtained in this laboratory indicated that pretreatment with CNS depressant drugs possessing neuroleptic activity facilitated this behavior, it appeared that aminergic mechanisms could be involved in mediating the self-administration behavior. Therefore, the effects of administering agents, known to centrally and/or peripherally alter aminergic activity, on cocaine self-administration behavior were ascertained.

Phenoxybenzamine and phentolamine are alpha adrenergic blocking agents and their ability to block peripheral alpha actions of norepinephrine and serotonin have been well documented [8]. However there is some question as to whether these agents block the effects of these substances in the central nervous system. Therefore, they are usually considered as being peripheral alpha adrenergic blocking agents. However depending on dosage and the route of administration sedation, hyperventilation, loss of time perception and convulsions have been reported in humans. These central effects could be direct in nature and unrelated to any neurotransmitter blocking ability.

Pargyline inhibits the enzyme monoamine oxidase which functions intraneuronally and extraneuronally in metabolizing norepinephrine, dopamine and serotonin; therefore, the effects of drugs which are dependent on the amounts of these neurotransmitters may be enhanced by pargyline treatment.

Alpha-methylparatyrosine (AMPT) inhibits the rate limiting step in the synethsis of dopamine and norepinephrine without affecting serotonin synthesis. Therefore drug effects based on dopamine and norepinephrine may be reduced by prior treatment with $A M P T$ [8].

Reserpine following an initial release of norepinephrine, serotonin and dopamine causes a depletion of neuronal levels of these substances [8]. Therefore like AMPT, it should reduce drug effects due to the release of these substances.

However, it must be recognized that not all of the effects of any drug capable of altering neurochemical transmission are necessarily attributable to this interaction with synaptic transmission. Their effects can also be direct in nature and furthermore effects which are thought to result from a direct action may later prove to have resulted from changes in monamine function or vice versa.

\section{METHOD}

\section{Animals}

The animals for this study were adult, drug-naive male rhesus monkeys weighing $3.8-5.6 \mathrm{~kg}$. Each monkey was housed individually in an open-faced experimental cubicle containing a response lever and stimulus light, and restrained by a stainless steel harness and arm assembly for the duration of the experiment [3]. The animals had free access to water and were fed at 8:00 a.m. and 4:00 p.m. After 7 days of adaptation to this environment, chronic indwelling jugular cannulae (i.d. $=0.81 \mathrm{~mm}$, o.d. $=$ $1.62 \mathrm{~mm}$ ) constructed of siliconized rubber were surgically implanted under pentobarbital anesthesia $(30 \mathrm{mg} / \mathrm{kg}$ slowly administered intravenously). Following surgery, 600,000 units of benzathine penicillin-G, mixed with 300,000 units of potassium penicillin-G (All Purpose Bicillin Injection, Wyeth Laboratories) was administered intramuscularly as a prophylactic measure against infection resulting from the surgical procedure.

\section{General Procedure}

For $72 \mathrm{hr}$ following surgery, each lever-press response exceeding $100 \mathrm{~g}$ of force and occurring during illumination of the stimulus light resulted in the intravenous administration of $0.2 \mathrm{cc} / \mathrm{kg}$ of sterile physiological saline. During this period the stimulus light was constantly illuminated except during an injection cycle. All lever-press responses were recorded on an Esterline Angus event recorder. Programmed injections were administered every $4 \mathrm{hr}$ in an effort to retard clot formation in the catheter. During this saline period, none of the animals emitted more than 12 lever-press responses within any $24 \mathrm{hr}$ segment.

The saline solution was then replaced by a saline solution of cocaine hydrochloride which was prepared every 5 days. The stimulus light continued to be illuminated $24 \mathrm{hr}$ a day for 5 days (except during an injection cycle). Each lever-press occurring while the light was illuminated resulted in the administration of $0.2 \mathrm{mg} / \mathrm{kg}$ of cocaine hydrochloride. As previously, programmed injections occurred every four hours. The duration of an injection cycle lasted from $35-50 \mathrm{sec}$ depending on the animal's body weight. Each animal initiated self-administration behavior, well within this 5 day period. Drug access was then reduced to a daily ( 7 days a week) $4 \mathrm{hr}$ session (10:00 a.m.-2:00 p.m.). Drug availability was indicated by the illumination of the stimulus light. Lever-presses in the absence of the illuminated stimulus light were recorded but had no consequence. Within 2 weeks daily drug intake was stable $(<10 \%$ change in daily drug intake over 5 consecutive sessions) for each animal. Furthermore, stimulus control of each animal was well evidenced by the small number of responses $(<10)$ emitted by each animal during the $20 \mathrm{hr}$ period separating successive sessions. Programmed injections continued to be administered every $4 \mathrm{hr}$ except during a daily session. If a catheter became inoperative during the course of the study, it was either replaced or a catheter implanted in the opposite internal jugular vein. If this occurred, a subsequent seven day reconditioning period was interposed to regain behavioral stability.

\section{Procedure Experiment 1}

This study utilized 8 animals divided into 2 groups of 4 animals each. The effects of acute pretreatment with pargyline and phentolamine on stable cocaine self-administration behavior were ascertained in one group and the effect of acute pretreatment with phenoxybenzamine and $\alpha$-methylparatyrosine determined in the other group. Five dosages of phentolamine and of phenoxybenzamine $(0.5-8.0 \mathrm{mg} / \mathrm{kg})$ were studied as were 5 dosages of pargyline $(1.0-100 \mathrm{mg} / \mathrm{kg})$. All dosages were calculated on the basis of the salt form. Four pretreatment dosages $(1.0-50 \mathrm{mg} / \mathrm{kg})$ of $\mathrm{DL} \alpha$-methylparatyrosine methyl ester (AMPT) (Regis Chemical Company, Chicago, Illinois) were investigated. All pretreatment solutions were prepared using a sterile physiological saline vehicle on the day on which they were administered. The solutions were refrigerated until $30 \mathrm{~min}$ prior to administration. Each animal in Group 1 
was tested on one occasion with each dose of phentolamine and pargyline; those in Group 2 were tested once with each dose of phenoxybenzamine and AMPT. Testing with all doses of the first drug was completed prior to initiating testing with the second drug. The sequence of dosage testing with each drug was randomized. The pretreatment drug was administered intramuscularly $5 \mathrm{~min}$ prior to session onset. The pretreatment drug volume was kept constant at $0.5 \mathrm{cc}$ with the concentration of the pretreatment solution being varied. Three sessions separated drug pretreatment sessions in which phentolamine or phenoxybenzamine were administered. Five days separated pargyline pretreatment sessions and 10 days separated AMPT pretreatment sessions. The various intervals were utilized in an attempt to insure no carry-over of drug effects from the previous pretreatment test session. Sessions in which $0.5 \mathrm{cc}$ of sterile physiological saline were administered intramuscularly $5 \mathrm{~min}$ prior to session onset were interspersed between drug pretreatment sessions (after the frequency of self-administration behavior had returned to base-line value) to control for conditioning of the pretreatment procedure. The percentage change in cocaine selfadministration seen in drug pretreatment sessions was compared to that which occurred in saline pretreatment sessions.

\section{Procedure Experiment 2}

Nine animals, randomly divided into 3 groups of 3 animals each, were utilized in this particular study. Each group was chronically treated with either $0.1,0.3$ or $1.0 \mathrm{mg} / \mathrm{kg}$ of reserpine. Treatment solutions were prepared daily using a vehicle of sterile physiological saline. Reserpine was administered intramuscularly $30 \mathrm{~min}$ following the daily drug access period. The injection volume was held constant at $0.5 \mathrm{cc}$. This treatment procedure was followed for 10 consecutive sessions in the groups receiving the 0.1 , and $0.3 \mathrm{mg} / \mathrm{kg}$ doses of reserpine. Reserpine, at a dosage of $1.0 \mathrm{mg} / \mathrm{kg}$, was administered for only 5 consecutive sessions because the dosage regimen was debilitating to the animals. The drug was administered post-session rather than presession in an attempt to produce the desired neurochemical effects without grossly altering animal behavior at the onset of and during the testing session. Prior to the onset of the reserpine treatment regimen, sterile physiological saline $(0.5 \mathrm{cc})$ was administered in a similar manner for 5 consecutive sessions. The self-administration behavior emitted during this saline control period was compared to that which occurred during and for 3 sessions after the discontinuation of reserpine treatment.

\section{RESULTS}

Figure 1 illustrates that acute pretreatment with either of the alpha adrenergic blocking agents, phentolamine or phenoxybenzamine, in dosages of $0.5-8.0 \mathrm{mg} / \mathrm{kg}$ did not significantly alter ( $p<0.05$ via Student's T test) the frequency of cocaine self-administration behavior. The data shown in this figure represents the values for the total amount of cocaine administered during the daily session; however further analysis also indicated that the frequency of the behavior was also not altered in any particular hour of the session. There was gross evidence of the peripheral actions of the adrenergic blocking activity of these compounds. The amount of salivation exhibited by these

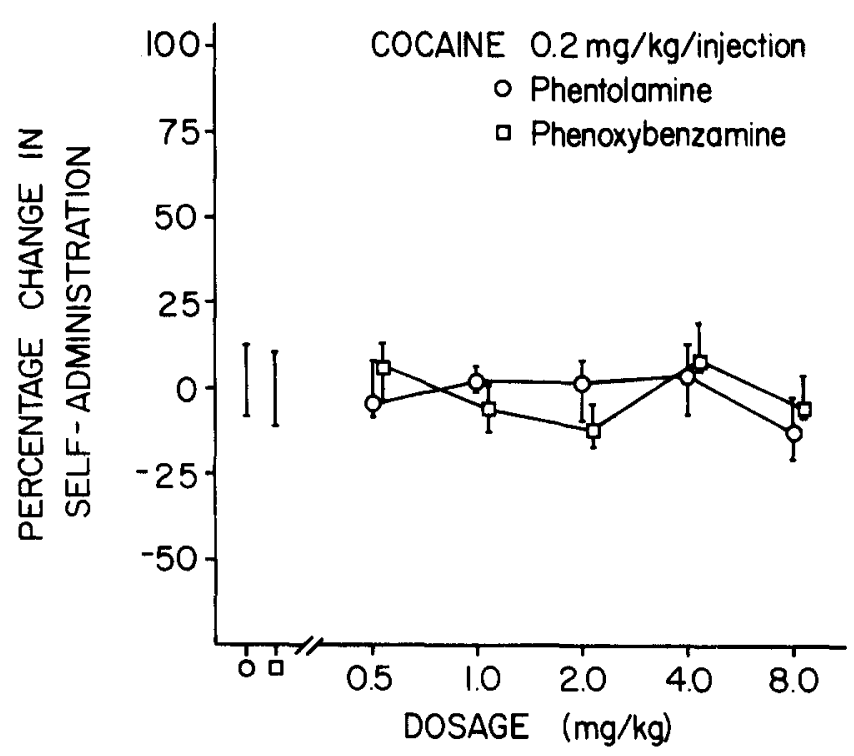

FIG. 1. Mean percentage change in cocaine self-administration as a function of the pretreatment dosage of phentolamine $(0-0)$ and phenoxybenzamine $(\square \longrightarrow-)$. Each point represents the mean of 4 animals and the vertical lines illustrate the range of change within these animals. The brackets at the left represent the range of change in cocaine self-administration which occurred following pretreatment with saline. Five of these control sessions were conducted in each animal.

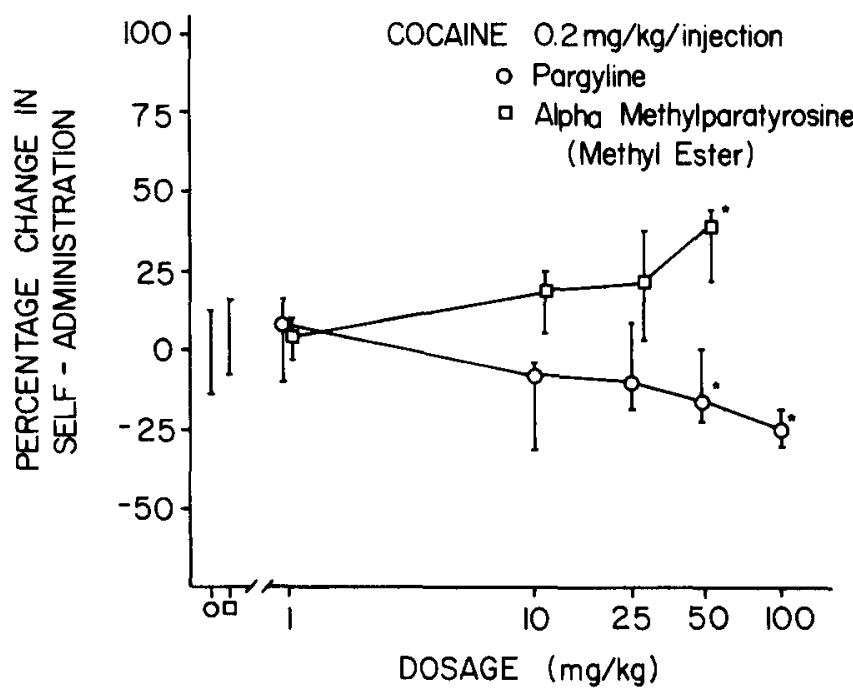

FIG. 2. Mean percentage change in cocaine self-administration as a function of the pretreatment dosage of pargyline $(0 \longrightarrow)$ and alpha methylparatyrosine, methylester $(\square \longrightarrow-\square)$. Each point represents the mean of 4 animals and the vertical lines illustrate the range of change within these animals. The brackets at the left represent the range of change in cocaine self-administration which occurred following pretreatment with saline. Five of these control sessions were conducted in each animal. An asterisk $\left(^{*}\right)$ denotes those points significantly different from saline $(p<0.05)$.

animals during saline pretreatment sessions as well as during non-pretreatment control sessions was much greater than in those sessions following pretreatment with either of these agents in dosages greater than $1.0 \mathrm{mg} / \mathrm{kg}$. 


\section{No. 331 (Cocaine $0.2 \mathrm{mg} / \mathrm{kg} / \mathrm{inj}$ )}
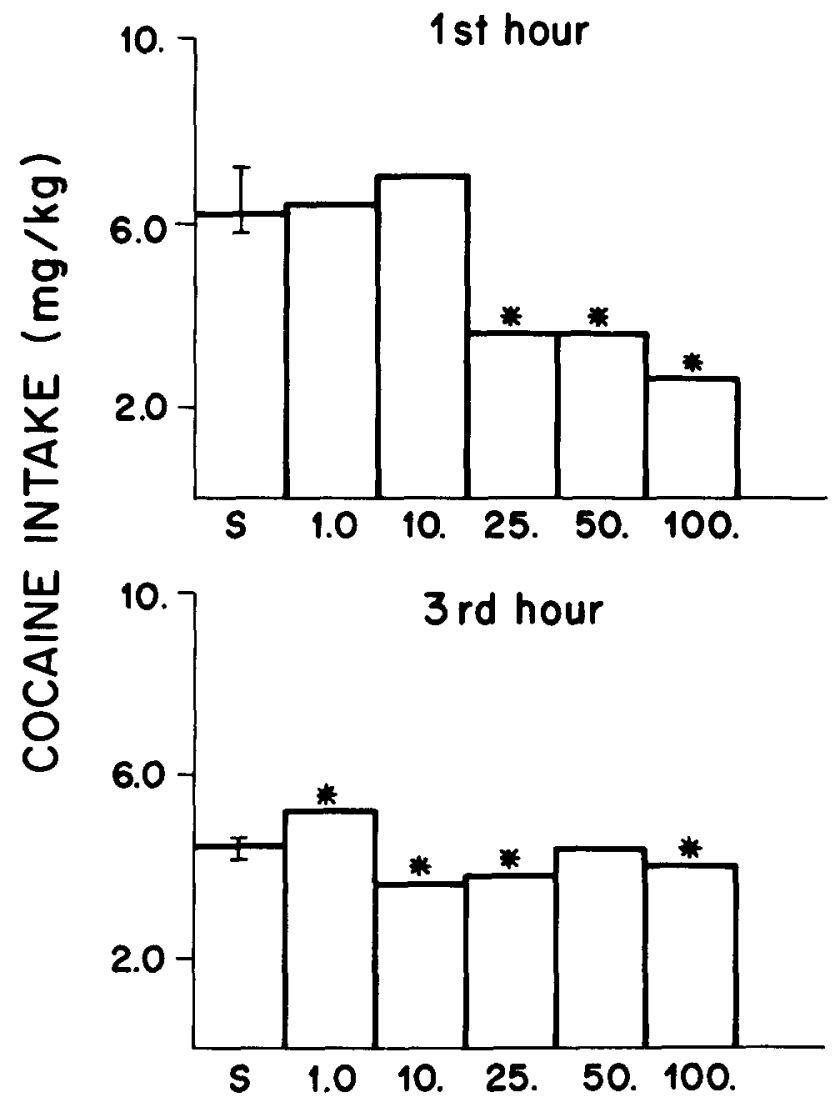
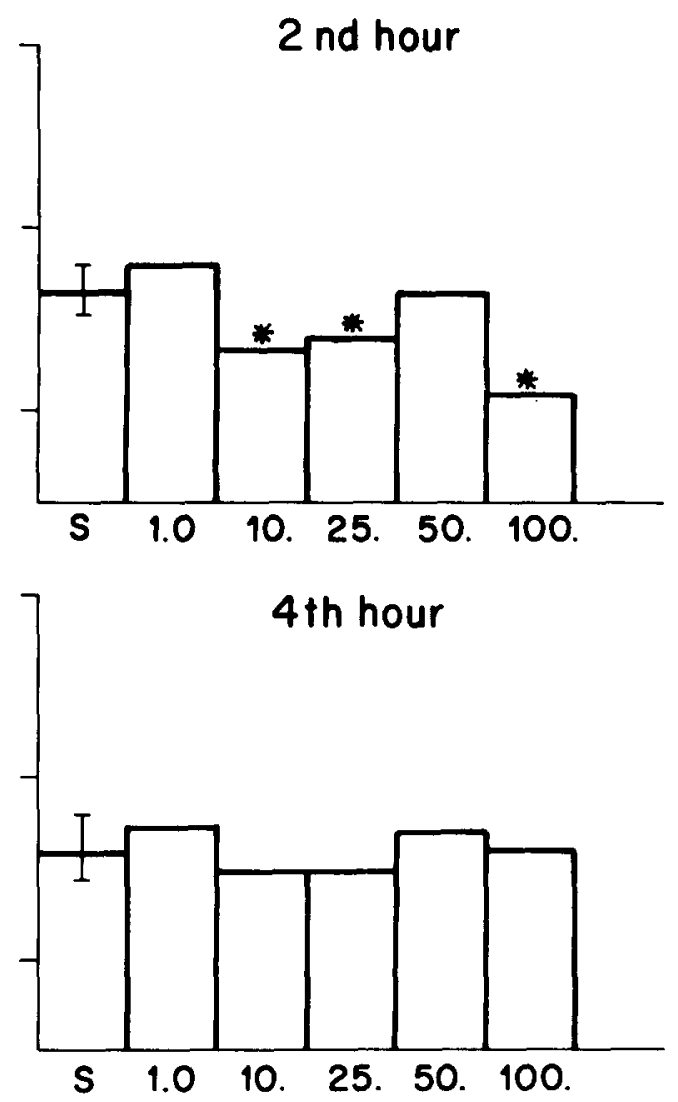

\section{PRETREATMENT DOSE OF PARGYLINE $(\mathrm{mg} / \mathrm{kg})$}

FIG. 3. Alteration in hourly cocaine intake in 1 animal as a function of pretreatment dosage of pargyline. The height of the bars illustrate the amount of cocaine self-administered during that hour, following pretreatment with a given dosage of pargyline. The height of the vertical bars over the letter $S$ represents mean cocaine intake in that period, following pretreatment with saline on 5 different occasions. The vertical lines represent the range of cocaine intake for these 5 control sessions. An asterisk $\left(^{*}\right)$ denotes those points significantly different from saline $(p<0.05)$.

The effects of acute pretreatment with the monamine oxidase (MAO) inhibitor, pargyline, on cocaine-selfadministration behavior is illustrated in Fig. 2. Pretreatment with $1.0,10$ and $25 \mathrm{mg} / \mathrm{kg}$ of pargyline did not significantly alter the frequency of cocaine self-administration behavior. However, pretreatment with 50 and $100 \mathrm{mg} / \mathrm{kg}$ of pargyline decreased the frequency of this behavior by an average of $15 \%$ and $25 \%$ respectively. This effect was evident in 3 of the 4 animals when treated with the $50 \mathrm{mg} / \mathrm{kg}$ dose and in each of the four subjects following treatment with the $100 \mathrm{mg} / \mathrm{kg}$ dose. During those sessions in which cocaine intake was depressed, the animals exhibited peripheral signs of sympathetic activity e.g., salivation and mydriasis; of a similar magnitude as occurred in saline control sessions during which more cocaine was selfadministered.

Figure 3 illustrates the time course of the effects of pargyline pretreatment on cocaine self-administration in a single animal. This animal was typical of the group treated with this substance. Although pretreatment with $1.0 \mathrm{mg} / \mathrm{kg}$ produced no overall change in cocaine intake, selfadministration behavior was slightly elevated in the third hour of the session. Drug intake during the other $3 \mathrm{hr}$ of the session was within the control range obtained from saline pretreatment sessions. Although pretreatment with $10 \mathrm{mg} / \mathrm{kg}$ produced no statistically significant change in cocaine self-administration for the entire session, cocaine intake during the second and third hours of the session were significantly reduced. Pretreatment with $25 \mathrm{mg} / \mathrm{kg}$ significantly decreased cocaine intake during the initial $3 \mathrm{hr}$ of the session but primarily during the first hour. However, total session drug intake across animals was not significantly reduced by this dosage. Pretreatment with $50 \mathrm{mg} / \mathrm{kg}$ decreased cocaine intake only during the initial hour of the session in this animal. However, in the other 3 animals intake was reduced in the first $3 \mathrm{hr}$ of the session. Pretreatment with $100 \mathrm{mg} / \mathrm{kg}$ decreased cocaine self-administration by at least $50 \%$ in the initial $2 \mathrm{hr}$ of the session in all 


\section{No. 280 (Cocaine $0.2 \mathrm{mg} / \mathrm{kg} / \mathrm{inj}$ )}

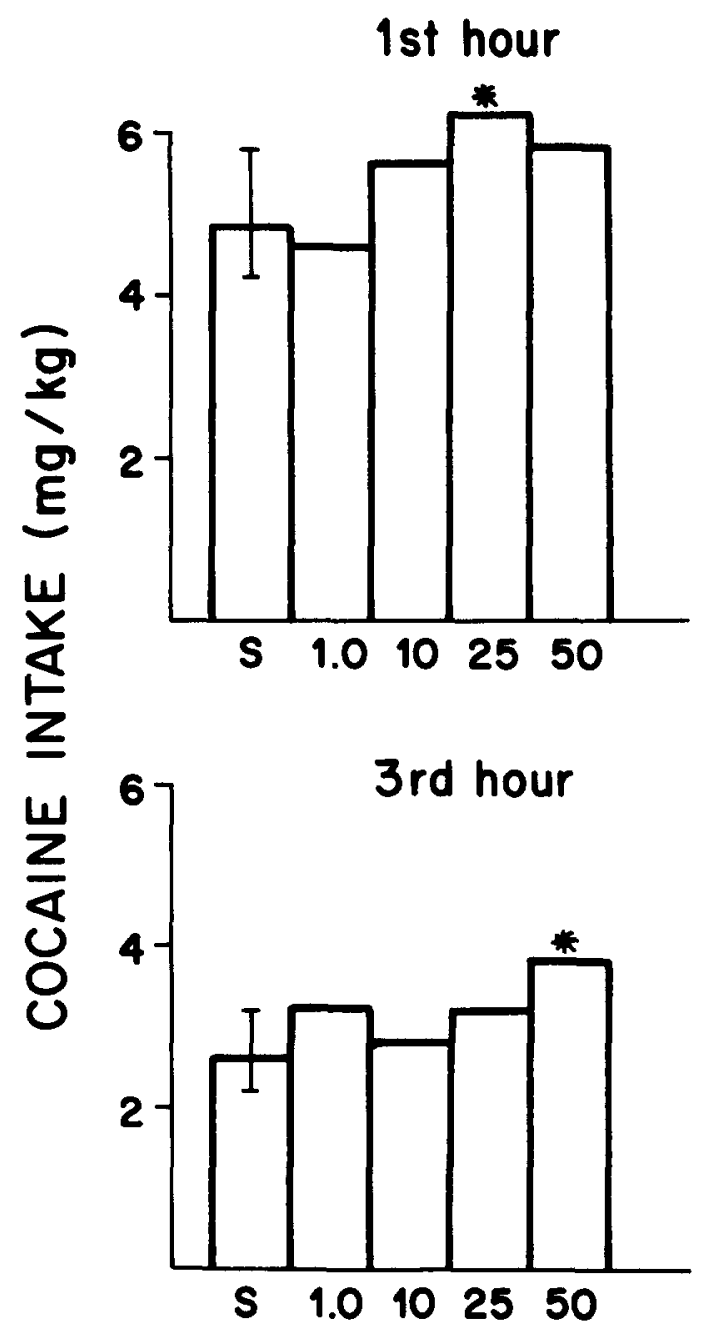

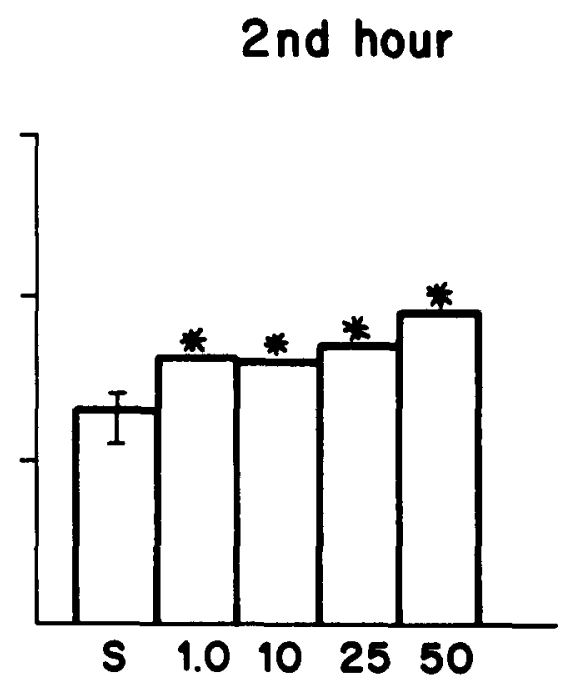

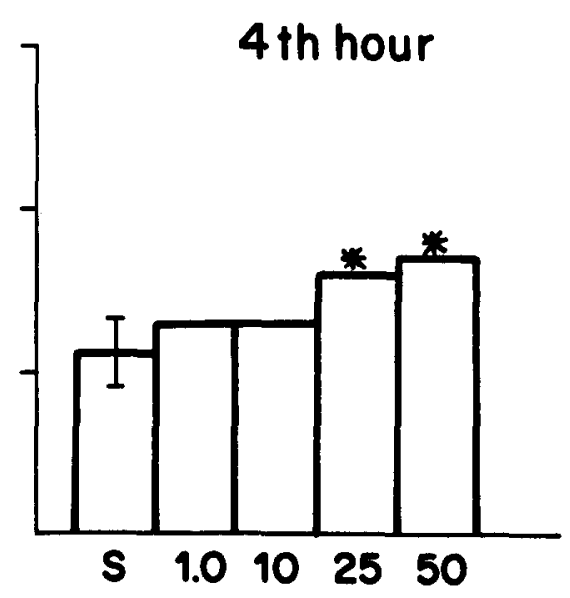

FIG. 4. Alteration in hourly cocaine intake in 1 animal as a function of the pretreatment dosage of alpha methylparatyrosine, methyl ester (AMPT). The height of the bars illustrates the amount of cocaine intake during that period, following pretreatment with a given dosage of AMPT. The height of the vertical bars over the letter $S$ represents mean cocaine in take in that period, following pretreatment with saline on 5 different occasions. The vertical lines represent the range of cocaine intake for these 5 control sessions. An asterisk $\left({ }^{*}\right)$ denotes those points significantly different from saline $(p<0.05)$.

animals but intake had returned to control values by the fourth hour in all animals and by the third hour in 2 of the animals.

The effects of acute pretreatment with the methyl ester of DL alpha methylparatyrosine (AMPT) on cocaine selfadministration are illustrated in Fig. 2. Pretreatment with $1.0 \mathrm{mg} / \mathrm{kg}$ did not produce any significant change in cocaine self-administration. Cocaine intake was increased by an average of $17 \%$ (range: $+5 \%$ to $+25 \%$ ) following treat- ment with $10 \mathrm{mg} / \mathrm{kg}$. Although this effect across animals was statistically insignificant, the increase seen in 3 of the 4 animals was greater than that which occurred during any control session in those same animals. Likewise, pretreatment with $25 \mathrm{mg} / \mathrm{kg}$ did not produce any statistically significant change in the frequency of cocaine self-administration across animals. However, cocaine intake was increased by an average of $19 \%$ (range: $+3 \%$ to $+37 \%$ ) and the effect was greater than that seen during any control 


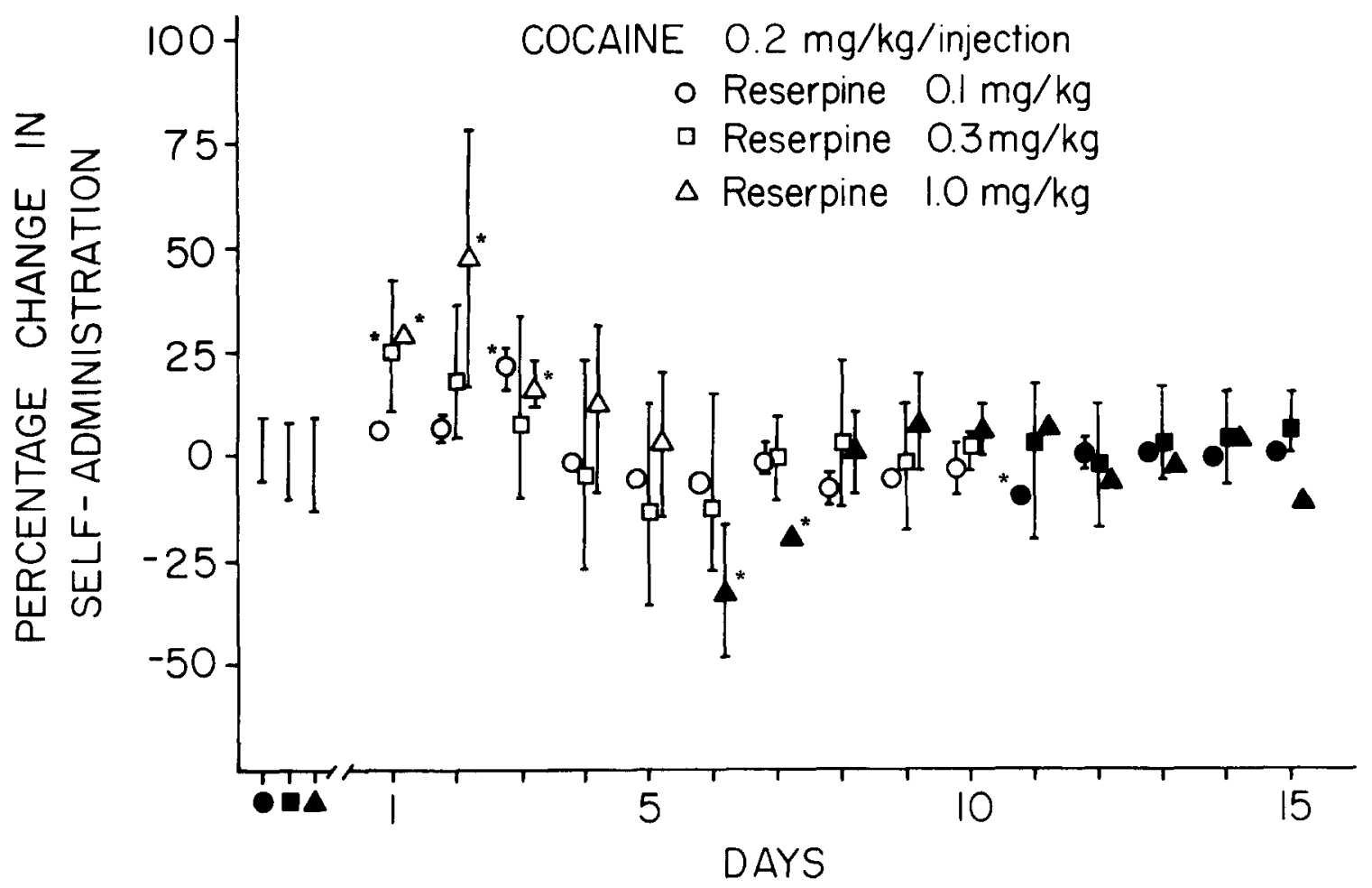

FIG. 5. Mean percentage change in cocaine self-administration as a function of the dosage of reserpine treatment and as a function of the duration of reserpine treatment. Each point represents the mean of 3 animals and the vertical lines associated with each point indicate the range of percentage change within these animals. In those instances where no range is indicated the point representing the mean covers the range. Open points represent sessions preceded by reserpine administration twenty hours previously. Closed points indicate no prior reserpine treatment. Those animals in which the 0.1 and $0.3 \mathrm{mg} / \mathrm{kg}$ dosages were examined were treated with reserpine for 10 consecutive days; whereas, the group treated with $1.0 \mathrm{mg} / \mathrm{kg}$ of reserpine received this dosage for only 5 consecutive days (see text). The vertical lines at the left represent the range of percentage change in each group of 3 animals, for the 5 sessions preceeding the onset of reserpine treatment. During this period saline was administered in the same manner and pattern as the subsequent treatment with reserpine. An asterisk $\left(^{*}\right)$ denotes those points significantly different from saline within each group $(p<0.05)$.

session in 3 of the 4 animals. A statistically significant increase in mean cocaine self-administration for the total session was produced by pretreatment with $50 \mathrm{mg} / \mathrm{kg}$ of AMPT. This effect occurred in all animals and the average increase was $40 \%$ and the range of the effect was $+23 \%$ to $+47 \%$.

The time course of the effect of AMPT on this behavior is illustrated in Fig. 4. The results represented in this illustration demonstrated those obtained from 1 animal which was fairly representative of the other 3 animals. Pretreatment with $1.0 \mathrm{mg} / \mathrm{kg}$ of AMPT increased cocaine selfadministration during the second hour of the session in this animal only. There was no other effect of this dosage of AMPT on hourly cocaine intake seen in this or the other 3 animals. Pretreatment with $10 \mathrm{mg} / \mathrm{kg}$ also produced an increase in cocaine intake during the second hour of the session but hourly drug intake was within control values during the other hours of the session. A larger increase in self-administration behavior during the second and third hours of the session was observed in the other 3 animals. Pretreatment with $25 \mathrm{mg} / \mathrm{kg}$ of AMPT increased cocaine intake slightly during the first hour of the session in the animal whose data is illustrated. This effect was absent in the other animals. This dose did significantly increase cocaine self-administration in the remaining $3 \mathrm{hr}$ of the session in 3 of the 4 animals. Pretreatment with $50 \mathrm{mg} / \mathrm{kg}$ of AMPT increased cocaine intake during the last $3 \mathrm{hr}$ of the session in each animal and was the most effective dosage tested.

The effects of the chronic administration of reserpine on cocaine self-administration are illustrated in Fig. 5. Treatment with a $0.1 \mathrm{mg} / \mathrm{kg}$ of reserpine $20 \mathrm{hr}$ prior to the daily experimental session for 10 consecutive sessions produced a statistically significant increase in cocaine intake in the third session following initiation of reserpine treatment. The average increase in cocaine intake on this day was $22 \%$ (range: $+18 \%$ to $+26 \%$ ). No significant change in drug intake occurred during the remaining 7 days of treatment with this dosage of reserpine. However, on the day following the cessation of reserpine treatment (Day 11) i.e.,; $44 \mathrm{hr}$ post-reserpine administration, mean cocaine intake was significantly decreased from initial saline control values by 9\% (range: $-7 \%$ to $-10 \%$ ). This effect was absent on the 4 succeeding control days.

Treatment with $0.3 \mathrm{mg} / \mathrm{kg}$ of reserpine increased mean cocaine intake by $25 \%$ (range: $+10 \%$ to $+42 \%$ ) during the first session following initiation of treatment. Cocaine intake was significantly increased in all 3 animals during this 
session. Tolerance developed to this effect of reserpine. The rate at which this tolerance occurred varied greatly within the animal group which is indicated in Fig. 5 by the great variability in drug effect. Intake had returned to control values by the second session in 1 animal and by the third in another but not until the seventh session in the third animal. Furthermore, in 2 of the 3 animals drug intake was reduced below control values on Days 4, 5 and 6 . The magnitude of this decrement ranged from $10 \%$ to $35 \%$ during this period. Cocaine self-administration returned to baseline values on Day 8 and remained there until reserpine treatment was discontinued. No significant changes in cocaine self-administration occurred during the 5 days after cessation of treatment with this dosage of reserpine.

Treatment with $1.0 \mathrm{mg} / \mathrm{kg}$ of reserpine produced a significant increase in cocaine self-administration in the first 3 sessions following treatment initiation. The mean increase was greatest on the second day $(x=31 \%$; range: $17 \%$ to $48 \%$ ). Drug intake returned to control levels in 2 of the 3 animals on Days 4 and 5 following the initiation of reserpine treatment. This dose of reserpine unlike the 0.1 and $0.3 \mathrm{mg} / \mathrm{kg}$ dosages produced ptosis, diarrhea, and a neuroleptic syndrome. Prior to session onset the animals exhibited ptosis and appeared lethargic and very sedated; however, at the onset of the stimulus associated with cocaine availability, i.e., stimulus light illumination, responding began with little delay and priming injections were unnecessary. Treatment with this dosage of reserpine was limited to 5 days since gross evidence of debilitation was present and the animals food and water intake were greatly decreased. The ptosis, diarrhea, and the neuroleptic syndrome were absent by the second day following cessation of reserpine treatment. Mean cocaine intake was significantly reduced below control levels on the first (32\%) and second (19\%) day following withdrawal of the reserpine. This effect was seen in each of the 3 animals. Drug intake returned to control values by the third day following discontinuation of reserpine treatment. Both the initial increase in mean cocaine intake which occurred during the initial 3 days of reserpine treatment and the decrement in mean cocaine intake seen following the cessation of reserpine administration were dose dependent and greatest in magnitude with the $1.0 \mathrm{mg} / \mathrm{kg}$ dose.

\section{DISCUSSION}

The lack of effect of treatment with either phentolamine or phenoxybenzamine on cocaine self-administration behavior apparently indicates that activation of peripheral alpha adrenergic receptors does not play any role in modulating behavior maintained by cocaine reinforcement. These agents have significant alpha adrenergic blocking action [8] and are clinically used for this effect. The lack of salivation, mydriasis and piloerection which normally accompanied the intake of cocaine was evidence that these agents in the dosages administered, were effective in blocking the peripheral alpha adrenergic actions of systemically administered cocaine. Similar dosages of phentolamine administered intramuscularly reduce the mean arterial blood pressure and increase heart rate in squirrel monkeys [7]. Therefore, there is no question that the dosage of phentolamine exerted peripheral effects. However, whether sufficient central levels of this drug were achieved by this route of administration is uncertain. It has been demonstrated that treatment with phenoxybenzamine does not block but rather slightly enhances the subjective euphoric effects of amphetamine administered i.v. [5]. This study used a single blind technique and involved 10 subjects with a prior history of intravenous amphetamine use. A self-rating scale was utilized for registration of the subject's feeling of euphoria after amphetamine. These authors hypothesized on the basis of the effect of this drug and others on amphetamine-based euphoria, that dopaminergic neurons were involved in mediating the subjective euphoric response. From the present data one can assume that perhaps central alpha-adrenergic systems either are not involved in mediating cocaine-based reinforcement or in mediating cocaine self-administration behavior or that sufficient quantities of phentolamine or phenoxybenzamine were not available to interact with these systems.

The decrement in cocaine self-administration seen following treatment with the monamine oxidase inhibitor pargyline may have occurred due to a potentiation of the effects of cocaine. Increases in the unit dosage of cocaine result in a decrease in the frequency of self-administration behavior $[4,12,15,17]$. Pargyline increases the intraneuronal levels of dopamine, serotonin and norepinephrine in dopaminergic, serotonergic and adrenergic nerves respectively by virtue of inhibiting metabolism of these biogenic amines by MAO. Pargyline treatment conceivably could result in the availability of even more dopamine, serotonin or norepinephrine in the synaptic cleft region following activation of the appropriate neurons. This increase in aminergic activity may increase the efficacy and duration of action of each unit dose of cocaine which results in a decrease in the frequency of self-administration. Therefore, it is feasible to consider that the effeects of cocaine might also be enhanced by the concurrent administration of an MAO inhibitor. It has been hypothesized that behavioral disrupting and/or aversive effects of cocaine which could be mediated by dopaminergic, serotonergic or adrenergic systems may function in controlling or limiting cocaine self-administration $[12,15]$. The pargyline data would support this concept. Pargyline may potentiate the ratelimiting effect and therefore reduce the frequency of cocaine self-administration behavior. Pargyline treatment did potentiate the peripheral actions of the cocaine i.e., quantitatively similar autonomic effects were produced by a smaller dose of cocaine following pargyline treatment. It was grossly evident that the decrement in cocaine selfadministration behavior was not due to motor incapacitation or sedation.

The increase in cocaine self-administration which occurred following treatment with AMPT has also been observed in rats which self-administered methamphetamine intravenously [11]. The present increase in self-administration behavior may have resulted from an antagonism or partial extinction of the reinforcing property of cocaine. If one decreases the unit dosage of cocaine a similar increase in responding results $[4,12,15,17]$. Further evidence to support this hypothesis has been demonstrated in humans. Treatment with AMPT $(0.5$ and $1.5 \mathrm{~g}$ which would be approximately equivalent to 7 and $21 \mathrm{mg} / \mathrm{kg}$ respectively in a $70 \mathrm{~kg}$ person) significantly antagonized the subjective euphoric response to intravenously administered amphetamine [5]. Tolerance developed to this amphetamine antagonism within 7 days of treatment. AMPT is an inhibitor of the enzyme tyrosine hydroxylase which is the enzyme which functions in the rate limiting step in the synthesis of dopamine and norepinephrine [14]. Whether 
the effects seen in this research were due to a depletion of central norepinephrine or of dopamine is not known since it has not been determined which of these transmitters is involved in mediating cocaine-based reinforcement.

However, another interpretation of the AMPT data would be that perhaps the decrease in dopaminergic or adrenergic activity may result in a decrease in those hypothetical actions of cocaine which may terminate its selfadministration. However, in view of the clinical experience, the former hypothesis concerning the mechanism of AMPT's effect on this behavior appears to be the more tenable. Furthermore, other investigators have demonstrated the ability of AMPT to block both primary and conditioned reinforcement associated with intravenous d-amphetamine self-administration in rats $[1,2]$.

The effects of chronic treatment with reserpine on cocaine self-administration are interesting. One could explain the initial rise in cocaine intake which was directly proportional to the dose of reserpine and whose latency was inversely proportional to the dose of reserpine, on the basis of this drug's ability to deplete monamines (serotonin, dopamine, norepinephrine). This effect would be similar to that of AMPT in that less dopamine and norepinephrine would be available for release from dopaminergic or adrenergic nerves. If those substances are involved either in mediating the reinforcing action of cocaine or in controlling cocaine self-administration then the initial increase in self-administration behavior is explainable.

The ability of cocaine to antagonize many of the effects of reserpine was evident in those subjects receiving the $1.0 \mathrm{mg} / \mathrm{kg}$ dose of reserpine. Ptosis, sedation, diarrhea in evidence at the onset of the session were rapidly antagonized by the cocaine within thirty minutes.

The decrease in self-administration behavior below control values which occurred when the reserpine was withdrawn is very difficult to interpret. If one assumes though that receptor sensitivity to these neurotransmitters has increased due to lack of these substances resulting from the effects of reserpine on amine metabolism, then upon removal of the reserpine the receptors may still be supersensitive to these substances for several hours. If the reinforcing action of cocaine is mediated by these substances then it would take less cocaine to produce the desired effect. Furthermore, if self-administration behavior is limited by actions of these same substances the behavior would be emitted at a reduced frequency even though less cocaine had been administered.

Such a supersensitivity mechanism may also be responsible for the development of tolerance to the initial increase in self-administration behavior, produced by reserpine. It has also been reported that tolerance develops to the depression in locomotor activity produced by reserpine in rats during a ten day chronic treatment regimen. By the end of the treatment period, reserpine enhanced locomotor activity as compared to controls [13]. The initial effect was greatest during the third and fourth daily session. Tolerance has been demonstrated to develop within seven days to the ability of AMPT to antagonize the reinforcing effect of intravenous amphetamine in humans, perhaps via a similar mechanism [5].

Tolerance does not develop to the increase in intravenous cocaine self-administration in monkeys produced by chlorpromazine during a 5 day treatment period [16]. One might expect these agents i.e., reserpine and chlorpromazine, to similarly effect this behavior since both are considered as neuroleptic agents and since both can antagonize many actions of psychomotor stimulants. They do differ in that whereas reserpine reduces levels of dopamine and norepinephrine, chlorpromazine supposedly blocks their receptors thereby not allowing the receptors to become supersensitive to the transmitter. Tolerance to the ability of the neuroleptics to block amphetamine-induced euphoria in humans has not been reported [5].

In general the data presented in this study tend to further implicate the central stores of dopamine and norepinephrine as functioning in mediating cocaine self-administration behavior. Although conceivably, serotonergic transmission may also influence this behavior and the effects of pargyline and reserpine pretreatment may be a reflection of this interaction. These two agents produce diametrically opposed changes in central serotonergic activity and produce opposite effects on the present behavior. Whether or not these biogenic amines mediate the reinforcing efficacy or mediate other effects of cocaine, which as well control the frequency of the behavior, remains to be ascertained. However, in view of the high correlation between the results of this study and those obtained by Gunne et al. (in humans) this study further signifies the acceptability of using the rhesus monkey as a model in which to investigate the reinforcing properties of the psychomotor stimulants.

\section{ACKNOWLEDGMENTS}

The authors express their appreciation to Mr. Robert Jackson for his technical assistance in conducting the research project and to $\mathrm{Mr}$. John Holbrook and Miss Judy Buelke for their assistance in the preparation of this manuscript. Furthermore the authors wish to thank the following drug companies for the complimentary supplies of drugs used in conducting this study: Abbot Laboratories, North Chicago, Illinois, Eutonyl (pargyline hydrochloride); Cibs Pharmaceutical Company, Summit, New Jersey, Regitine (phentolamine mesylate), (reserpine); Smith, Kline and French Laboratories, Philadelphia, Pennsylvania, Dibenzyline (phenoxybenzamine hydrochloride).

\section{REFERENCES}

1. Davis, W. M. and S. G. Smith. Alpha-methyltyrosine to prevent self-administration of morphine and amphetamine. Curr. ther. Res. 14: 814-819, 1972.

2. Davis, W. M. and S. G. Smith. Blocking effect of alphamethyltyrosine on amphetamine based reinforcement. $J$. Pharm. Pharmac. 25: 174-177, 1973.

3. Deneau, G., T. Yanagita and M. Seevers. Self-administration of psychoactive substances by the monkey. Psychopharmacologia (Berl.) 16: 30-39, 1969.
4. Goldberg, S., F. Hoffmeister, U. Schlichting and W. Wuttke. A comparison of pentobarbital and cocaine self-administration in rhesus monkeys: Effects of dose and fixed ratio parameter. $J$. Pharmac. exp. Ther. 179: 277-283, 1971.

5. Gunne, L., E. Anggard and L. E. Jonsson. Clinical trials with amphetamineblocking drugs. Psychiat. Neurol. Neurochir. 75: $225-226,1972$. 
6. Holtzman, S. and R. Jewett. The role of brain norepinephrine in the anorexic effects of dextroamphetamine and monamine oxidase inhibitors in the rat. Psychopharmacologia (Berl.) 22: $151-161,1971$.

7. Kelleher, R. T., W. H. Morse and J. Herd. Effects of propranolol, phentolamine and methylatropine on cardiovascular function in the squirrel monkey during behavioral experiments. J. Pharmac. exp. Ther. 182: 204-217, 1972.

8. Nickerson, M. Drugs inhibiting adrenergic nerves and structures innervated by them. In: The Pharmacological Basis of Therapeutics 4th Edition, edited by L. Goodman and A. Gilman. New York: Macmillan Company, 1970, pp. 549-562.

9. Pickens, R. and W. Harris. Self-administration of d-amphetamine by rats. Psychopharmacologia (Berl.) 12: 158-163, 1968.

10. Pickens, R., R. Meisch and L. McQuire. Methamphetamine reinforcement in rats. Psychon. Sci. 8: 371-372, 1967.

11. Pickens, R., R. Meisch and J. Dougherty. Chemical interactions in methamphetamine reinforcement. Psychol. Rep. 23: $1267-1270,1968$.
12. Pickens, R. and T. Thompson. Cocaine-reinforced behavior in rats: Effects of reinforcement magnitude and fixed ratio size. J. Pharmac. exp. Ther. 161: 122-129, 1968.

13. Pirch, J. H. and R. H. Rech. Behavioral recovery in rats during chronic reserpine treatment. Psychopharmacologia (Berl.) 12: $115-122,1968$.

14. Weissman, A., B. Koe and S. Tenen. Antiamphetamine effects following inhibition of tyrosine hydroxylase. J. Pharmac. exp. Ther. 151: 339-352, 1966.

15. Wilson, M. C., M. Hitomi and C. R. Schuster. Psychomotor stimulant self-administration as a function of dosage per injection in the rhesus monkey. Psychopharmacologia (Berl.) 22: $271-281,1971$.

16. Wilson, M. C. and C. R. Schuster. The effects of chlorpromazine on psychomotor stimulant self-administration in the rhesus monkey. Psychopharmacologia (Berlin) 26: 115-126, 1972.

17. Woods, J. and C. R. Schuster. Reinforcement properties of morphine, cocaine and SPA as a function of unit dose. Int. J. Addict. 3: 231-237, 1968. 